IWONA KOTELNICKA

\title{
Alfred Nossigs Dramen. Identitätsprojektionen und biographische Bezüge
}

Wszechstronnie uzdolniony, dzisiaj zapomniany lwowski Żyd Alfred Nossig (18641943) zostawił po sobie teksty literackie w języku polskim i niemieckim. Artykuł analizuje trzy spośród jego dramatów pod kątem problematyki tożsamościowej i odniesień biograficznych do skomplikowanych losów ich autora, zastrzelonego w getcie warszawskim przez żydowskich bojowców.

Der vielseitig begabte, heute vergessene Lemberger Jude Alfred Nossig (1864-1943) hinterließ literarische Texte in Polnisch und Deutsch. Der Aufsatz analysiert drei seiner Dramen im Hinblick auf die Identitätsproblematik und biographische Fragen in Nossigs kompliziertem Leben, dem ein im Warschauer Ghetto von jüdischen Kämpfern vollstrecktes Todesurteil ein Ende setzte.

The multitalented, today forgotten, Lemberger Jew Alfred Nossig (1864-1943) left literary texts in Polish and German. This paper analyses three of his dramas from the point of view of the identity-problems and the biographic items in Nossig's complicated life, ended with an execution by the Jewish fighters in the ghetto of Warsaw.

\section{Biographischer Hintergrund}

Mit dem Bann des Schweigens belegte ihn der Dichter des Warschauer Ghettos, Jizchak Katzenelson, wie die Rabbiner früherer Zeiten Abtrünnige mit dem großen Cherem belegten: Alfred Nossig, ein „Nothing“, ein Nichts, wie der amerikanische Dramatiker Lazarre S. Simckes den Namen in seiner Groteske Nossig's Antics spielerisch verdreht, ein „Nothing“, weil der Verges- 


\section{Iwona Kotelnicka}

senheit preisgegeben. ${ }^{1}$ Doch für die polnischen, an Geschichte interessierten Leser ist er kein ,Nothing': ein deutscher Spion und Gestapo-Kollaborateur, den die jüdischen Kämpfer von der Untergrundorganisation ŻOB im Warschauer Ghetto 1943 exekutiert hatten. ${ }^{2}$ Der Spionage- und Kollaborationsvorwurf ist zwar nicht zweifelsfrei, aber in der Öffentlichkeit fest verwurzelt. Nossigs wenig bekanntes Leben wurde durch den Tod zum selbstverständlichen, beiläufig zitierten Symbol des Verrats. ${ }^{3}$

Nossig - Literat, Literaturtheoretiker, Journalist, Bildhauer, Librettist, Sozialwissenschaftler, Kulturmanager, Politiker -, geboren 1864 im galizischen Lwów (Lemberg), wuchs in einem aufgeklärten jüdischen Milieu auf. ${ }^{4}$ Wie viele jüdische Jungen besuchte er das deutsche Gymnasium in der galizischen Hauptstadt, dem polnisch dominierten Lemberg. Er nahm aber auch an der polnischen Kultur regen Anteil. Die galizische Autonomie erhöhte seit 1867 die Attraktivität der polnischen Akkulturation für die dortigen Juden, und der junge Nossig gehörte trotz seines familiären jüdisch-deutschen Hintergrunds zu den Befürwortern der Assimilation an die polnische Kultur, engagierte sich im jüdisch-polnischen Verein Agudas Achim - Przymierze Braci (,Bündnis der Brüder') und redigierte dessen Zeitschrift Ojczyzna. Aber bereits in seiner Lemberger Zeit wechselte er zum Zionismus über und gründete den Verein Zion mit. 1886, mit 22 Jahren, verlässt er seine Heimatstadt, um sein Studium in Czernowitz und Zürich fortzusetzen. Anschließend

1 KaCENELSON (198:79). Das Lied aus dem Epilog (Nummer XIV) ist auf den 9.-13. Januar 1944 datiert, etwa ein Jahr nach der Exekutierung Nossigs. Der Autor hat den Krieg nicht überlebt, vgl. SiMCKES (O.J.); das Stück wurde in New York 2004 gespielt, Einsicht in das Manuskript vom Verfasser freundlicherweise ermöglicht.

2 MARK (1959:67); vgl. Ringelblum (1988:42; hier Anmerkung der Redaktion). Nossig gilt als Ghetto-Kollaborateur in mehreren Erinnerungen der Überlebenden, allerdings wurden diese nach dem Krieg mit dem Wissen über das vollstreckte Urteil aufgeschrieben. Unklar ist der Charakter von Nossigs Kontakten mit der Gestapo / dem SD. Die dezidierte Anklage von MARK (1959) wird z.B. von Almong (1987) in Frage gestellt. Sie wiederholt sich aber in The Holocaust Encyclopedia, s. TzuR (2001:133).

3 Vgl. das Interview mit Marcel Reich-Ranicki in der Tageszeitung Gazeta Wyborcza. Duży Format, s. KuŹNIAK / TUSZYŃSKA (2008).

4 Biographische Informationen $\mathrm{zu}$ Nossig und weiterführende Hinweise auf Archivalien verdanke ich vor allem dem Aufsatz von PIBER (1978); zu den Lemberger Jahren vgl. MENDELSOHN (1971), zur Biographie auf Deutsch auch KOTELNICKA (2009). 
übersiedelt er nach Wien, später nach Paris und 1899 nach Berlin, wo er zuerst als habsburgischer Untertan und nach dem Ersten Weltkrieg bis August 1933 als polnischer Staatsbürger lebt. Nach dem misslungenen Versuch, in der Schweiz Fuß zu fassen, kehrt er für kurze Zeit in das wiedererrichtete Polen zurück. Doch bald fährt er wieder nach Berlin, wo er wahrscheinlich etwa zwei Jahre bleibt. Aber 1937 schreibt er an den Pianisten und Politiker Ignacy Jan Paderewski schon aus Prag. Im Herbst 1939 dokumentiert der Vorsitzende der Jüdischen Gemeinde (des ,Judenrats'), Adam Czerniaków, die Anwesenheit Nossigs im besetzten Warschau, wo er ihn auf Wunsch der deutschen Besatzer im Judenrat anstellt. ${ }^{5}$

Die Faszination, die von Nossigs kompliziertem Leben ausgeht, legt bei der Beschäftigung mit seinen Texten die Frage nach der literarischen Auseinandersetzung mit seiner Identität nahe: nicht nur nach einer nationalen, religiösen bzw. ethnischen Selbstbestimmung des Verfassers sowie nach der kulturellen Verwurzelung seiner Texte, sondern auch danach, welche Vorstellungen vom Menschsein er in seine Figuren projiziert. Ferner stellt sich dabei die Frage, inwiefern das aus den literarischen Texten rekonstruierte Ideengerüst Nossigs praktisches politisches Handeln beleuchten kann. ${ }^{6}$

Nossig schrieb Polnisch und Deutsch. Er hinterließ nicht viele literarische Werke, alle stammen aus der Zeit vor dem Ersten Weltkrieg, aber er gehört zu den wenigen Autoren, die in der jüdisch-polnischen Presse nach dem Ersten Weltkrieg als Vorläufer der jüdisch-polnischen Literatur akzeptiert wurden und nicht ,„,der Pest des Mechesismus' verfallen waren“.7 In der polni-

$5 \quad$ Vgl. CZERniaKów (1983:56; Notiz vom 17.10.1939).

6 Es geht um mehrere politische Aktionen, in denen Nossig sich als Vermittler anbot und hin und wieder als falscher Vermittler betrachtet wurde: angefangen mit der deutsch-französischen Verständigung um 1900 (NossIG 1900a), über Gespräche in der Türkei im Ersten Weltkrieg, ferner polnisch-jüdische Gespräche 1920, polnisch-deutsche Gespräche in der Frage des schlesischen Plebiszits (AKTEN ZUR DEUTSCHEN AusWÄRTIGEN POLITIK 1918-1945: Nr. 118) bis zu seiner ,europäischen Aktion' in den 1920er Jahren, deren Ziel eine europäische Vereinigung (zeitweise ,Europäische Union` genannt) war, und nicht zuletzt um seine letzte Lebensetappe im Warschauer Ghetto; s. Frommelt (1977:16-41).

7 Prokop-JANIEC (1992:20). ,Meches` - eine verächtliche Bezeichnung des getauften Juden. Auf Polnisch erschienen zwei Dramen, auf die ich mich im Folgenden beziehe: Nossig (1885 und 1888), und außer kleineren Dichtungen zwei größere Prosatexte: Nossig (1885 / 1888) und (1892). Von seinen im Druck auf Deutsch erschienenen Dramen - Abarbanel (1906), Göttliche Liebe, (1899 / 1903), Die Tragödie des Gedankens (1904), Die Hochstapler (1902), Die Rette- 


\section{Iwona Kotelnicka}

schen Kultur wird paradoxerweise sein deutsches Libretto zu der einzigen Oper von Ignacy J. Paderewski Manru. Lyrisches Drama in 3 Aufzügen (1901) am häufigsten erwähnt. Er publiziert auch zahlreiche soziologische, jüdische und sozialpolitische Schriften. Journalistisch ist er in der polnischen, österreichischen und deutschen Presse tätig, auch als Kommentator des theatralischen Lebens. 1905 gibt er in Berlin eine recht umfangreiche, ästhetische Schrift Die Erneuerung des Dramas und 1907 die Broschüre Moderne jüdische Dichtung heraus. ${ }^{8}$

\section{Tragedia myśli}

NossIGs dramatisches Debüt über Giordano Bruno mit dem ungewöhnlichen Titel Tragedia myśli [Die Tragödie des Gedankens], geschrieben 1885, an der Schwelle zu seinem nationaljüdischen Umschwung, erlangte einen relativ hohen Bekanntheitsgrad über Galizien hinaus. Rezensionen erschienen in den meinungsbildenden Zeitschriften in Warschau: in Prawda und Przeglad Tygodniowy (vgl. Z. 1885 und BoHUSZ 1885). Eine rege Aufnahme dieses Fünfakters - der künftige Literat, Kritiker und Germanist KAROL IRZYKOWSKI (2001:188, 223, 240f.) nennt Nossig in seinem Tagebuch in einem Atem mit Grabbe, Schiller und Goethe - war sicher mit einem gewaltigen Tabu-Bruch verbunden: gegen die Fesselung des öffentlichen Diskurses durch die katholische Kirche, gegen christliche Dogmen und gegen die auf der christlichen Tradition aufgebaute Sexualethik. Die Subversivität des Dramas bekräftigten zusätzlich die Zensurbehörden sowohl im habsburgischen

rin (? spätestens 1905), Die Legionäre (? 1910) - werde ich mich nur Abarbanel zuwenden. Nach der Auskunft Nossigs wurden die drei letztgenannten Dramen in Berlin aufgeführt. Vgl. StaAtsbibliotheK ZU Berlin. Preussischer KultuRBESITZ: Handschriften. Nachlass Brümmer. (Herrn Konrektor Franz Brümmer. 9.8.1913. Brief von A. Nossig). Sein Drama Rafat Kruzoe (Polnisch) wurde wahrscheinlich nicht veröffentlicht.

8 Die Erneuerung des Dramas (190 Seiten) ist als eine moderne und zum Teil normative Poetik konzipiert, in der sich Nossig auf u. a. Aristoteles, Lessing, Freytag und Hebbel bezieht. Darin bespricht er außer den „Allgemeinen Gesichtspunkte[n]“ auch „Die Prinzipien des neuen Dramas“, hier „Die Charaktere“ (z.B. „Die Größe der Charaktere“, „Realismus und Idealismus in der Charakterzeichnung. - Die Überlebensgröße“, „Ergänzende Regeln und Beispiele“), „Die Form des Dramas“ (z.B. „Wissenschaftliche Begründung der rhythmischen Form“) und „Die Reform des dramatischen Verses“. 
Galizien als auch im zaristischen Russisch-Polen durch die ausgesprochenen Verbote gegen den Text.

Das Erstlingsdrama Nossigs eröffnet einen Prolog, in dem der Dichter und der Gelehrte ein ästhetisches Programm proklamieren: ein Bündnis zwischen Kunst und Wissenschaft, aus dem eine neue ,gesunde' Kunst hervorgehen soll, eine harmonische Synthese der Schönheit und Wahrheit, der ein dekadenter Ästhetizismus und Naturalismus als krankhafte Überwucherungen in der Kunst weichen müssen. Das ,neue Werk' geht über das Individuelle hinaus und widerspiegelt die natürliche Partizipation des Einzelnen an der nationalen und universellen Kultur. Die Kunst ist zwar mit der Religion verwandt, als das Werk der Seele, „die glaubend lieben will“, aber „die Gottheiten“ der Religionen wechseln sich ab, während in der Kunst „,das Wahre, Ewige und Allgemeine“ eine greifbare Gestalt annimmt. ${ }^{9}$ So wird der absolute Status der wahren Kunst als eine Art Überreligion begründet: im Gegensatz zu vergänglichen und relativen Religionen.

Gleich am Anfang umfasst Giordano Bruno, der Protagonist des angekündigten ,neuen Werkes", als monologisierender Visionär mit seinem gesamten Wesen, „mit Liebe“ und „mit dem Gedanken“ das All. Eine kopernikanische Vision der kosmischen Ordnung tut sich ihm im ganzheitlichen Akt der Kommunikation mit der „Weltseele“, mit der All-Einheit auf. Der Erkennende und Fühlende, Gelehrte und Dichter ist auch ein Tat-Mensch, denn er will seine Erkenntnis unter die Menschen bringen und dadurch die Welt verändern. Seine Botschaft lautet: Es gibt nichts außer dieser Welt, und das menschliche Paradies kann nur hier geschaffen werden. Damit entfallen religiöse Anfeindungen, und der neue Glaube, von ihm verkündet, gilt nicht ,einem Stamm“ oder einem „Weltteil“, sondern „,dem Menschen“. Sein Gebot des Lebens, der Liebe, der natürlichen Vermehrung und der Naturforschung antizipiert den „Frieden“ und ,eine neue Welt der Liebe“ (NosSIG 1885:8f.).

Das Weltbild Giordano Brunos wird im Drama immer weiter ausgebaut, mit Details versehen, die seine Subversivität gegenüber den bestehenden Religionen noch mehr herausstellen. Es ist ein Monismus, der die Dualität zwischen Materie und Geist aufhebt und von der ,Natur' alle Gesetze ableitet. Auch das Menschenbild, das Nossig in seinem Erstlingsdrama zeichnet, ist im monistischen Weltbild eingebettet. Der Renaissance-Mensch Giordano Bruno, Gelehrter, Dichter und Geliebter, lebt ein ganzheitliches Leben, in

9 Nossig (1885:5f.). Alle Übersetzungen aus dem Polnischen stammen von der Verfasserin 


\section{Iwona Kotelnicka}

dem Intellekt, Emotionen und Körper eine Einheit bilden. Zu modernen, vielseitigen Renaissance-Persönlichkeiten entwickeln sich auch die Hauptfiguren in den Prosawerken Nossigs, die im Europa des 19. Jhd.s spielen. Umso deutlicher ist hier zu sehen, dass die ganzheitliche Harmonie als ein modernes Lebensprojekt gemeint ist, in dem vielseitiges Studium, Pflege der Künste (verschiedener Künste), Körperkultur, Liebe und Sex zum erfüllten, über den Egoismus hinauswachsenden Menschentum führen. Eine ,Vollendung' erfährt sein Giordano Bruno durch die Frau. Mann und Frau werden bei Nossig zu zwei mythisch verklärten Elementen, die erst zusammen die Ganzheit der Natur bilden: hier Stein und Pflanze, in seinem Pamiętnik Daniela [Aus dem Tagebuch Daniels, 1885] Meer und Erde. Zu Nossigs harmonischem Ganzheitsideal gehört ein leidenschaftliches Ja zur Liebe, auch der körperlichen Liebe ohne religiöse oder konventionelle gesellschaftliche Sanktionierung. So trifft auch Giordano Bruno auf eine - seine Frau, Beatrice, die nicht nur weiblich-fürsorglich, sondern auch imstande ist, seinen Geist zu umfassen und ihn zu ,ergänzen“(NOSSIG 1885:32f. und 1885 / 1888:41, 71, 74).

Trotz der universellen Perspektive reflektiert dieses Drama indirekt Nossigs biographischen Hintergrund - die nationale und religiöse Vielfalt mit ihren Konflikten, mit Ausgrenzung, Abgrenzung, der Unterdrückung von Andersdenkenden - und im Besonderen die Situation der Juden im Modernisierungsprozess. Es kommt der Identifikationsnot bei denjenigen entgegen, für die traditionelle Gemeinschaften und Sinnsysteme ihre stabilisierende Funktion verloren haben. Einerseits ein antipartikularistischer Monismus und andererseits ein individueller Lebensentwurf mit Einbeziehung der weltlichen Wissenschaft und der , sinnlichen' Seite der Wirklichkeit - Kunst, Körperkultur, Naturschönheit, Liebe - beide konnten für die jungen sich emanzipierenden Ostjuden Identifikationsangebote darstellen und den Entwurzelten helfen, sich die ,fremde' Welt zu eigen $\mathrm{zu}$ machen und die traditionell vernachlässigte sinnlich-ästhetische und weltliche Seite der Wirklichkeit als Teil des sinnvollen sinnlich-geistigen Ganzen aufzuwerten. Andererseits ist es offensichtlich, dass Nossig in der Auseinandersetzung mit dem asketischen, ja zelibatösen Lebensideal des Christentums das im jüdischen Gesetz verankerte ultimative Gebot der Eheschließung als das der Natur gerechte(re) sieht. Hier steht das zwar nicht direkt zur Debatte, aber eine solche Schlussfolgerung drängt sich auf, und sie wird in seinem Studium über die Sozialhygiene bestätigt (NOSSIG 1894:58). 
In ihren gesellschaftlichen Konsequenzen kann also diese vereinheitlichende, dem Zeitalter der Naturwissenschaften verbundene Weltsicht den emanzipatorischen Schritt aus der eigenen traditionellen jüdischen Gemeinschaft rechtfertigen, die ,fremde" Welt als die eigene fundieren, aber auch von dieser verlangen, dass sie sich im Einklang mit der Natur öffnet, denn der Monismus nivelliert Unterschiede und Grenzen, und zwar ist die Nivellierung ,kosmischen' Ursprungs und erst an zweiter Stelle ein ethisches Gebot (NOSSIG 1892:438). Dieser universelle, antipartikularistische Zug des Monismus bietet Chancen für ein friedliches Zusammenleben mit einer parareligiösen Sanktion. Andererseits verspricht er, alle Religionen als partielle, historische Welterklärungen abzulösen, und stattdessen setzt er einen übergreifenden Sinn (Alleinheit der Natur), durch die Kunst mitteilbar, der eine Alternative zu der Anpassung an fremde Sinn-Systeme, zum Aufgehen im Fremden oder Verharren im Eigenen, Alten bildet.

Anders als in der Suche nach der Ganzheit um die Jahrhundertwende (wie bei Hofmannsthal oder Buber), wo der moderne Zerfall der Welt(erkenntnis) und der damit verbundene Sinnverlust den Hauptimpuls zu der Suche geben, geht Nossig nicht von der Kritik des wissenschaftlichen Erkennens aus, sondern sieht darin eine der Quellen für sein emanzipatorisches Ganzheitskonzept. Die mit Mitteln der Wissenschaft zu erforschende natürliche, ,kosmische“ Ordnung wird vital bejaht, und ihre Erforschung eröffnet eine Perspektive für eine von der Natur abgeleitete Gesellschaftsordnung ohne ideologische, religiöse Schranken.

Giordano Brunos Genie stellt ihn intellektuell, vital und ethisch über das menschliche Maß: nicht wie andere Menschen „aus einer Handvoll Erde“, sondern aus „Feuer“ wurde er geschaffen (Nossig 1885:49). Er, der Forscher, ist zugleich ein Prophet, der eine messianische Zeit prophezeit, in der die ganze Welt miteinander kommunizieren wird (auch Pflanzen und Tiere). Die Verheißungen der mit Liebe, Schönheit, Kraft, Weisheit und Wahrheit durchtränkten Welt mischen sich mit Mahnungen gegen die Widersacher der Wahrheit. Auch die Messianität der übermenschlichen Figur Brunos wird angedeutet: Die schwangere, fast bis zum Wahnsinn getriebene Beatrice vergleicht ihre Aufopferung für Bruno mit Opfern, die „andere Frauen“ für Christi dargebracht hatten (NossIG 1885:93). Für Bruno selbst wird Christus zu einer Identifikationsfigur, mit der er hadert: Christus, ein Mensch wie er, Bruno, irritierend wegen des - in dessen Augen - unberechtigten religiösen Kults. Und doch verwandelt sich die argwöhnische Verachtung Brunos gegen den, der zu Gott „,von einem Schüler gemacht“ wurde, obwohl er im Leben 


\section{Iwona Kotelnicka}

nichts „Göttliches“ getan habe, in eine nachdenkliche Antizipation des eigenen Schicksals (NossIG 1885:29). Und selbst der Gedanke über das (Nichts-)Tun Christi in dessen Menschenleben wird revidiert, denn er sei ein Beweis, dass der Tod allein auch eine große Tat sein könne. Noch in demselben Akt erwägt Bruno den Sinn eines Todes für die Wahrheit. Sein Tod bereitet sich als ein Opfertod vor, und Bruno beschreibt sein Opfer in Bildern der Naturprozesse - der Tod ist ein „Dünger“, der ,das Aufkeimen des neuen Lebens beschleunigt" (NossIG 1885:72). Diesem scheinbar szientistischen Bild liegt eine messianische Erwartung zugrunde, die sich allmählich im fünften Akt des Dramas konkretisiert.

Während der Scheiterhaufen vorbereitet wird, verkündet ein eingetroffener Prophet, dass zur Hinrichtung des Mönchs von Nola in Sodom [!] der Ewige Jude, Ahasveros, erscheinen werde (Giordano Bruno stammte aus Nola). Wenn der zum Tode Verurteilte - ,wie Christus, der Herr“ - vor Erschöpfung auf seinem letzten Weg zusammenbrechen und um Wasser bitten werde, werde ihm Ahasveros seinen Becher reichen, und der Gemarterte werde dem Herumirrenden (,tułacz') ,seine Erinnerung und seine Rache an dem betrügerischen Sodom“ weitergeben (NOSSIG 1885:89). In den weiteren Szenen geht diese Prophezeiung in Erfüllung, aber mit einer Einschränkung: Es ist ein Pilger, der dem durstigen Bruno das Wasser reicht. Der Name Ahasveros wird im Drama nicht mehr erwähnt. Der Pilger-Ahasveros rollt nun in seinem Monolog eine messianische Vision auf: große Leiden, die „Geburtswehen“- die nach der jüdischen Tradition dem Kommen des Messias vorangehen - gingen bald zu Ende. Die „Menschheit“ möge sich freuen, denn es kämen schon „lichtere Zeiten“, und seine „Bürde“ (das ewige Wandern) werde leichter. Die Zeit seiner „Erlösung“ ziehe herauf, er höre „die Hymnen der nahenden Verbrüderung“ (NossIG 1885:91).

Nach der Legende soll Ahasveros, der Ewige Jude, bis zum zweiten Kommen Christi in der Welt rastlos wandern. Doch Bruno gebietet dem (vermeintlichen) Ewigen Juden, dass er in sein „Heimatland“ zurückkehren soll: ein Hinweis auf die Messianität der Zeit und auch auf die des Giordano Bruno. Bruno, obwohl er sich selbst als den „,neuen Erlöser“ bezeichnet, hofft erst auf einen ,neuen Erlöser“, der geboren werden soll. Ihm selbst sei nicht gelungen, ,den neuen Glauben“ zu stiften. Er ist eine messianische Figur, aber kein Messias, der das zweite Mal kommt, eher wie Christus, der sich Aufopfernde, dessen Opfer die Weltgeschichte vorantreibt, aber nicht vollendet. Die Weitergabe der Botschaft Brunos, des reinen Wahrheitsstrebens, wird dem Ewigen Juden auferlegt: Der neue Erlöser soll aus dem „Samen“ 
des Ewigen Juden in dessen Heimatland geboren werden. Das Wort „Heimatland“ wird in einem kurzen Abschnitt dreimal wiederholt, zweimal als „Geh zurück in dein Heimatland!“ (Nossig 1885:103) Ahasveros' „Heimatland“ ist Palästina. Eine verschlüsselte zionistische Botschaft kann darin durchaus gelesen werden: Mit der Rückkehr in das „Heimatland“ ist auch die messianische Erwartung verbunden, dass von dort aus ein allgemeiner (hier: szientistischer) Glaube ausgeht, der „mit dem ewigen Gedanken“ im Einklang stehen würde. Gedenkt man der Worte des Propheten über die Weitergabe der „Erinnerung“ des „Märtyrers“ und dessen „Rache an dem betrügerischen Sodom" an Ahasveros, dann wird der Ewige Jude zur zentralen Figur in der Aufrechterhaltung der Botschaft Giordano Brunos. Das wäre eine literarischmythische Interpretation der Auserwähltheit der Juden als derjenigen, die Erinnerung und Wahrheit aufbewahren und weitergeben.

In dem die Harmonie und All-Einheit heraufbeschwörenden Weltbild des Prologs und der Monologe Brunos deckt der Pilger zum Schluss eine Paradoxie auf: die All-Einheit der Natur schlösse den Kampf von gegensätzlichen Kräften in sich ein (NOSSIG 1885:105). Dadurch würde auch Giordano Brunos Tod und Leben relativiert und seine erträumte Zeit der allgemeinen Eintracht nur ein unerreichbares Ziel, für das man einen immerwährenden Kampf führen muss. Nossigs Bruno wäre damit eine faustische Gestalt, und zwar nicht nur in seinem Streben nach Wahrheit und Glück der Menschheit, sondern auch in mehreren Andeutungen: Beatrice - Gretchen, Luzifer Mephisto, schließlich in dem Gefühl des erfüllten Lebens im Augenblick des Todes.

Nossigs Figuren werden, nicht nur in diesem Drama, auffallend synkretisch konstruiert: ein Bruno, der die Züge eines Faust und eines Christus trägt, der einmal Stein, dann wieder Feuer ist; ein Luzifer, der an Prometheus und Mephisto erinnert, eine Beatrice - die zugleich Gretchen und Ophelia ist; im Roman Jan Prorok der Pole Jan, der an manchen Stellen wie ein jüdischer Junge dargestellt wird, in Pamiętnik Daniela: Daniel, ein Engländer, der sich zum Schluss als Prophet und Führer armer „schwarzer“ (jüdischer?) Massen sieht, und schließlich der von Giordano Bruno prophezeihte Erlöser: Moses, Kopernikus, Hannibal, Dante und Homer in einem (Nossig 1885:73f.). Der Synkretismus erfasst nicht nur literarische Figuren, sondern auch Handlungsorte: Rom wird zu Sodom, und im Lemberg des Romans Jan Prorok schimmert Jerusalem durch. Sind diese Kontaminationen nicht aus der Handlung erklärbar, so doch aus Nossigs Monismus und dem ästhetischen Postulat, Individuelles, Nationales und Universelles künstlerisch in einem zu erfassen, 


\section{Iwona Kotelnicka}

und gerade diesen synkretischen Zeichen kommt eine besondere Bedeutung zu: als Erlöser-Figuren oder als Zeichen der Universalität der übermittelten Botschaft. $^{10}$

Tragedia myśli erschien in der Zeit des sich anbahnenden zionistischen Umbruchs im Leben des jungen Nossig. Er steht noch den polnischen assimilatorischen Kreisen nahe, und die jüdische Schicht im Drama wird in den Pressebesprechungen angesichts des provokanten vitalen antichristlichen Freidenkertums scheinbar nicht bemerkt. Dass sie dem Verfasser wichtig gewesen sein musste, sehen wir in seiner Publizistik, wo er seine universalistischen Ideen als religiösen Synkretismus mit voraussichtlich zentraler Rolle eines szientistisch gestrafften Judaismus direkt formuliert:

Sollten wir daran zweifeln, daß eine Vereinigung menschlicher Religionen erfolgen wird? Ist es denn nicht wahrscheinlich, daß der Mosaismus, angesichts der minimalen Zahl seiner Dogmen, kurzer und einfacher, angesichts des absoluten Fehlens von Wundern, einer universellen Religion denselben Gefallen tun wird [...], wie die englische Sprache mit ihren kurzen Wortstämmen und wenigen Ausnahmen bestimmt ist, einer universellen Sprache einen Dienst zu erweisen? (Nossig 1886:374)

Die im Drama anklingende Problematik der jüdischen Auserwähltheit wird in dem zitierten Artikel ebenfalls angesprochen: als Aufgabe einer vorbildlichen Gestaltung des künftigen Gemeinwesens, das auf die Allgemeinheit ausstrahlen sollte. Diesem Gedanken bleibt Nossig auch in der späteren zionistischen Publizistik treu (NossIG 1905:3 und 1905b:97f.). Einer ähnlichen Interpretation der Auserwähltheit begegnen wir im assimilatorischen Kreis des Agudas Achim, und viel später auch bei dem Zionisten MARTIN BUBER (1920: 167, 172, 176). Der Wechsel von der Assimilation an die polnische Kultur zum Zionismus scheint im Falle Nossigs keinen radikalen Charakter zu haben: weder auf der menschlichen Ebene noch auf der ideellen. Sein Konzept der individuellen und nationalen „Eigenarten“, die in die universelle Kultur einmünden, ließ sich assimilatorisch und zionistisch realisieren. Die beiden Wege finden eine ,natürliche" Rechtfertigung in seiner Broschüre über die Lösung der ,jüdischen Frage': als Absorbierung eines Teils der Juden durch die umliegenden Völker und auf der anderen Seite als Konsolidierung des

10 Den von deutschen Juden viel gelesenen Roman Spinoza Berthold Auerbachs (1837) beschließt eine Vision, in der in einer Gestalt Spinoza, Christus und Ahasver zusammenschmelzen oder eben schillern. Dieser Romanschluss ist so suggestiv, dass man darin eine Inspiration für ähnlich uneindeutig-synkretisch konstruierte Figuren Nossigs vermuten kann. 
national bewussten Teils zum Aufbau eines nationalen Gemeinwesens (Nossig 1887:86). War der Tenor des Giordano-Bruno-Dramas antipartikularistisch und messianisch optimistisch, unterstreicht der zionistische Nossig die Grenzen ziehende Kraft der „Eigenarten“, was ihn nicht hindert, in der praktischen Politik immer wieder auf die „Einigung“, „die Versöhnung der Gegensätze“" hinzuarbeiten (vgl. Anm. 6).

In der zeitgenössischen Rezeption wird weder die weltlich abgewandelte, evolutive Messianität noch der für die Emanzipation der Juden interessante, identitätsstiftende Aspekt des Monismus angesprochen. Selbst in der assimilatorischen Warschauer Zeitschrift Izraelita belässt es der Rezensent dabei, die freidenkerische Tendenz und vor allem ,die auf die Massen wirkende Form“ allgemein zu loben (GE 1885:274). Auch über die Gestalt des Ahasver-Pilgers gehen die Besprechungen hinweg, so dass die Auseinandersetzung mit spezifisch jüdischen Fragen im Drama völlig unbemerkt oder nicht artikuliert blieb. Was die Aufmerksamkeit anzieht, ist der Aufbau, die innere Logik und die kulturelle Verwurzelung des Textes. Im Vorwort zu Tragedia myśli verweist der Herausgeber auf deutsche Vorbilder des Dramas. Anspielungen auf den Faust in der ideellen Schicht und in den Figuren, auf Schillers Don Carlos in der Gestalt des Großinquisitors, ferner auf Karl Gutzkows Uriel Acosta als das große Freidenker-Drama mit einer sich aufopfernden Frauenfigur waren lesbare Inspirationen für Tragedia myśli. ${ }^{11}$ Für Nossigs Rückbesinnung auf die Renaissance gibt es gerade in der deutschen Kultur des 19. Jhd.s zahlreiche Quellen, auch wenn sich dazu polnische Parallelen in den 1880er Jahren finden. ${ }^{12}$ Eine andere - möglicherweise wegen der politischen Zensur - unerwähnte ,polnische Spur' scheint in den Text verwoben zu sein. Brunos Hadern mit Christi wird beim polnischen Leser in mancher Formulierung ein fernes Echo des romantischen Monologs

11 Gutzkows Drama wurde in Lemberg 1879, 1883 (dreimal), 1886 (zweimal) und ebenfalls in den folgenden drei Jahren im Teatr Polski gespielt, was von großer Popularität des Stückes zeugt; MARSZAŁEK (1992:155; 1993:87) und MARESZ / SZYDŁOWSKA (1993:57, 116, 121).

12 Nossig ging viel weiter im Antiklerikalismus als zum Beispiel die ebenfalls antiklerikale und fast zeitgleiche historische Dramendichtung $Z$ przeszłości. Fragmenty dramatyczne [Aus dem Vergangenen. Dramenfragmente, 1881] von Maria Konopnicka oder Jan Kasprowicz in seinem Poem Giordano Bruno (1884). Die Renaissance des Interesses für Giordano Bruno ist noch einmal um die Jahrhundertwende (Monisten-Bund) zu verzeichnen, als Nossig seine Tragedia myśli [Die Tragödie des Gedankens] 1904, über zwanzig Jahre nach der polnischen Fassung verlegte. Doch ein deutscher Erfolg blieb anscheinend aus. 
Iwona Kotelnicka

aus der Totenfeier von Mickiewicz hervorrufen. Beide - der Dichter-Prophet Konrad von Mickiewicz und der Forscher-Prophet Bruno - rebellieren gegen Gott, der eine in seiner anmaßenden und der andere in der legitimen Hybris des Übermenschen. Selbst die Tradition des Versdramas mit nicht streng logisch aufeinanderfolgenden, in der Stimmung abwechselnden Szenen darf auf Mickiewicz - bei aller Unverhältnismäßigkeit des Vergleichs - verweisen. Faszinationen für die polnische Romantik teilte der junge Nossig mit seinen Weggefährten aus dem Umkreis der assimilatorischen Zeitschrift Ojczyzna, deren „ersten Jahrgang er mit Artikeln chauvinistisch-nationalen Inhalts füllte", wie der angehende Kritiker und Literat WILHELM FELDMAN (1887:382) nach Nossigs zionistischer ,Konversion“ schreibt. Romantische Faszinationen und positivistisches Weltbild verbinden ihn gerade mit dem zitierten Feldman.

\section{Król Syon}

Folgte man Nossigs eigener Unterteilung der jüdischen Literaten „,in zwei Hauptgruppen [...] eine bewußt jüdische und eine unbewußt jüdische, eine offene und eine maskierte, eine, die ihren Stolz darein setzt, unter eigener Flagge zu segeln, und eine, die ihren jüdischen Ursprung tunlichst verwischen möchte“ (NossIG 1907:4), so wäre er als Dramatiker erst mit seinem Król Syjonu [Der König von Zion] von 1886 (Nossig 1888) und dem nur auf Deutsch geschriebenen Abarbanel (Nossig 1906) der ersteren, offen jüdischen zuzurechnen. Die beiden Dramen greifen jüdische geschichtliche Stoffe auf und diskutieren unter der geschichtlichen Maske Probleme der zeitgenössischen Juden.

In dem Fünfakter Król Syjonu, von einer Warschauer Jury 1886 ausgezeichnet und 1888 in Lemberg aufgeführt, erleben wir die zur Neige gehende Herrschaft des jüdischen Helden Bar Kochba, der für die jungen Zionisten eine Leitfigur werden sollte - wie im Prager Verein, der seinen Namen trug. Nossigs Bar Kochba ist eine mit seinem Giordano Bruno gewissermaßen verwandte messianische Dramenfigur: ein übermenschlicher Koloss, dessen Vitalität ihm Stärke verleiht und ihn über seine Mitmenschen erhebt. Sein Charisma bannt Männer und Frauen, und er selbst fällt derselben Kraft zum Opfer, die die Quelle seiner Stärke ist: Eine Spionin der Römer dringt in seine Gemächer ein, verführt ihn und erschleicht seine Geheimnisse. Alles an ihm ist übermenschlich, auch seine Herausforderung Gottes und seine Untaten, die der vitalen Quelle entsprießen, nicht dem berechnenden Bösen. 
Auch diese Gestalt schillert synkretisch: im hebräischen Betar erscheint als römische Spionin Dejanire. Sie ist es, die Bar Kochba verzaubert, selbst wenn sie sich später in ihn verliebt und von seiner Hand stirbt. Ihr Name verweist auf den jüdischen Heros Bar Kochba als Inkarnation des Herakles, und diese Anspielung wird durch den Selbstmord Bar Kochbas in der vorletzten Szene verstärkt: er benutzt dafür eine Giftschlange, die er in seinem Gemach hielt...13

In den Gestalten Bar Kochbas und Dejaniras erkennen wir eine Wirkung des in Lemberg recht intensiv rezipierten Friedrich Hebbels. ${ }^{14}$ Hebbels große Figuren dürften Nossig als Folie für seine Heroen gedient haben: Judith und Holofernes aus Hebbels Judith entsprechen dem Paar Dejanira und Bar Kochba - wieder bei aller Unverhältnismäßigkeit des Vergleichs. Die beiden Paare erliegen ihrer dunklen vitalen Energie, deren eine Seite der starke Wille ist und die andere der nicht bezwingbare Eros. Die eigenen Motivationen bleiben für sie zum Teil im Dunkeln. Doch Nossig konstruiert das Drama anders als Hebbel, denn um die Handlung mit dem Protagonisten wird eine Diskussion geführt: von den Protagonisten aus der Umgebung Bar Kochbas, die die jüdische Politik in Betar zu beeinflussen versuchen und mit ihrer politischen Haltung eine Brücke zur Gegenwart schlagen. Der wichtigste unter ihnen ist Rabbi Akiba, ein Realpolitiker, der im Gegensatz zum edlen und charismatischen Propheten Eleazar die Vertreibung der Samariter als einen notwendigen Schritt zur Selbstverteidigung akzeptiert (NoSSIG 1888:92). Polemisch auch gegenüber dem Hofdiplomaten Ismael, der ,scheinbare Gegensätze“ vereinigen, „Widersprüche“ schlichten will, meint Akiba: ,[...] [I]m menschlichen Leben, wie in der Natur, soll [...] nicht die künstliche Eintracht, die eine Niederlage der beiden Elemente ist, sondern ein Sieg entscheiden." (NosSIG 1888:120) Die weltanschauliche und strategische Abgrenzung Akibas gegen den wortgewandten Opportunisten und, wie es sich später herausstellt, Verräter Ismael, fällt am schärfsten aus, aber es gibt auch andere Trennungslinien, weniger scharf gezeichnet: Der charismatische

13 Allerdings gibt es eine Schlange auch in der jüdischen Überlieferung zu Bar Kochba, s. GRAETZ (1908:148).

14 SAdKowsKa (2007: 63-74); ReHM (1924:61-83). Im 19. Jhd. gab es in Deutschland wenigstens ein Bar-Kochba-Stück von Paul Möbius (1863) und in Polen eines von Felicjan Faleński Syn Gwiazdy [Der Sohn des Sterns, 1871]. MendelSOHN (1971:529) zitiert aber ein in den Lemberger Kreisen gelesenes hebräisches Bar-Kochba-Stück mit eindeutiger antiassimilatorischer Tendenz von Jehuda L. Landau, das (1884 erschienen) Nossig inspiriert haben könnte. 


\section{Iwona Kotelnicka}

Eleazar und der konservative, verknöcherte Meir halten sich an den ,Buchstaben“ des Gesetzes, im Gegensatz zu Akiba, der den Grundsatz ,Liebe deinen Nächsten' ins Zentrum seiner Lehre setzt und sich in der Interpretation der Schrift freier bewegt. Die beiden erkennen die Messianität Bar Kochbas nicht an, weil ihm die in der Schrift angekündigten Attribute der Messianität fehlen. Anders Akiba: Zwar gebraucht er nicht den tradierten Begriff ,messianisches Werk' in Bezug auf Bar Kochba wie der schmeichelnde Opportunist Ismael, aber er versucht die Messianität in eine moderne Formel zu bringen und diese vorsichtig doch auf die Gegenwart Judeias zu beziehen. Das, was als ,messianisches Werk' bezeichnet werde, werde sich langsam vollziehen, nicht auf einmal, ,[...] und zweifellos wird der Name eines großen Menschen mit diesem Werk in Verbindung stehen“ (NossIG 1888:122). Und die Sündhaftigkeit des großen Menschen muss seine Größe nicht in Frage stellen, wie sie diese bei biblischen Großen nicht in Frage gestellt hatte. Auf den Einwand des charismatischen Eleazar, dass Bar Kochba die Prophezeihung Jesajas nicht erfüllt, entgegnet Akiba:

Jesaja begehrte das Glück seines Volkes und aller anderen Völker. Moses und Christus veredelten die Menschheit, indem sie ihr Volk veredelten; unser verstreutes und unterdrücktes Volk ist wie ein Mensch mit unterbundenen Adern. Zerreißen wir die Fesseln, und die Kraft und Fruchtbarkeit werden sich bei uns wieder einstellen! Wir werden neue Wohltäter der Menschheit heranzüchten, die das Werk unserer Väter fortführen werden. Zerreißen wir diese Fesseln, und die Prophezeihungen Jesajas werden wahr! (Nossig 1888:123)

Nossigs Bar Kochba ist eben eine Gestalt, die die römischen „Fesseln“ der Fremdherrschaft, aber auch die inneren der jüdischen Gesetze ,zerreißt“ und seine „Fruchtbarkeit“ exzessiv demonstriert. Sein Akiba, der Typ eines politisch engagierten Intellektuellen, steht zu dem mit vitaler Kraft begnadeten Bar Kochba im Glauben, dass er ,,dadurch die Zeiten näherbringt, wo die verbrüderten Völker einen neuen Tempel für den Gedanken Jesajas errichten“ (NossIG 1888:123f.), und wohlwissend, dass seine Treue zu Bar Kochba den Tod bedeutet. Doch auch hier, wie in Tragedia myśli, ist der nahende Tod kein Ende: Der königliche Popanz Abimelech bezeichnet Akiba als „,den lebendigen und unsterblichen, soweit der Geist unsterblich ist" (NossIG 1888:124). Wir sehen in der Dramenfigur des Akiba einen Exponenten der Auseinandersetzung um die Messianität und die Auserwähltheit der Juden, die Nossig auch publizistisch führte, und zugleich einen Politiker, der eine Position zwischen den Extremen (dem orthodoxen Meir und dem zu jeder Anpassung bereiten Ismael) einzunehmen versucht, einen Realpolitiker mit durchaus ideellen Zielen. Akibas unorthodoxe Interpretation der Messianität 
Alfred Nossigs Dramen. Identitätsprojektionen und biographische Bezüge

als Opfer fordernde Evolution und der Auserwähltheit als Fortführung des universellen Werkes der „Veredelung“ der Menschheit, in der Moses und Christus [!] die großen jüdischen Leitfiguren sind, bildet einen Kommentar zum dramatischen Geschehen. Gerade in der ,messianischen Vernunft ${ }^{\text {}}$ Akibas findet man die politische Position Nossigs, die er selbst als ,Realpolitik' bezeichnet: in seiner Broschüre über den ,Weltfrieden', in der er 1900 ein auf der Achse Deutschland-Frankreich aufgebautes europäisches Bündnis vorschlägt, und später in verschiedenen ,Aktionen', die eine rationale Argumentation mit prophetischem Eifer verbinden (s. Anm. 6).

Gemessen an den wohlwollenden Stimmen gegenüber Tragedia myśli, stieß Król Syonu bei der positivistischen Kritik anscheinend auf wenig Verständnis. Maßstäbe für die Größe der szenischen Gestalten waren pragmatisch, und der lüsterne Bar Kochba erfüllte sie nicht; der dramatische Aufbau war zu verworren, ohne logische Konsequenz. Die auf der Bühne vorgeführten Diskussionen über die Messianität wurden entweder marginalisiert oder als unverständlich abqualifiziert. (ANONYM 1888a:5f.) Die Botschaft des Dramas sei insgesamt unübersichtlich dargestellt, schrieb der Kritiker in Gazeta Narodowa. Der Versuch Nossigs, zentrale jüdische Themen (Messianität, Auserwähltheit und zeitgenössische Misere) in die universelle Perspektive einzuordnen, blieb in der Besprechung nicht unbemerkt. (ANONYM 1888:3)

\section{Die Erneuerung des Dramas: Aszension}

Während die Entwicklung der zionistischen Bewegung von einer Reflexion über die moderne jüdische Kultur und Kunst begleitet wird, hält sich Nossig eher zurück, ein jüdisches ästhetisches Programm zu formulieren, was aber nicht heißt, dass er sich nur der Politik verschreibt. ${ }^{15}$ Seine Ästhetik des Dramas, 1905 veröffentlicht, ist eine universelle, um nicht zu sagen, eine ,kosmische', in die eine nationale einmündet. Sie zu umreißen, macht Nossig einen kulturphilosophischen Bogen, indem er die Grundlagen der Kultur in geologischen Bildern als aufeinanderliegende biologische Schichten beschreibt „die unveränderliche Natur des Menschen: [...] der Urgranit“, „Rassen“, „Nationen“, „die harte Steinschicht gewisser Instinkte, Eigenschaften und Fertigkeiten" -, auf denen ebenfalls schichtweise die Kultur ruht (zuoberst

15 Entgegen PROKOP-JANIEC (1992:125) ist Nossig an Kultur interessiert und steht auch dem Kulturzionismus (Demokratische Fraktion) nahe, nur anders als die jüngere (,jungjüdische') Generation. 
Iwona Kotelnicka

„die weiche, bewegliche Alluvialschicht der Mode“). Nossigs Erneuerung des Dramas will in die Tiefe greifen, denn die Bedeutung der Literatur hängt davon ab, auf welche Schicht „,er moralischen Geologie“ sie zielt: ,[...] [I]n der Naturgeschichte wie in der Geschichte wird die Bedeutung durch die Unveränderlichkeit und die Allgemeinheit gemessen." (NossIG 1905a:15f.) Er wird in seiner Ästhetik des Dramas die räumliche und zeitliche Universalität anstreben, die tiefen unveränderlichen Schichten im Menschen ansprechen. Das bedeutet in seiner Auffassung eine Abkehr sowohl vom Naturalismus als auch von der dekorativen Kunst und eine Hinwendung zur Poesie und zum „Monumentaldrama“ (auch „Höhendrama“, „Drama großen Stils“ genannt), das eine „Größe der Stoffe und der Typen; Adel der Form“ und rhythmisierte Sprache kennzeichnen sollen (Nossig 1905a:26). Für diesen Stil, der das Schöne, Erhabene mit dem Wahren verbinden soll, will er die von dem Lateinischen ,ascendere" (,hinaufsteigen") abgeleitete Bezeichnung ,Aszension“ prägen und erläutert das Gemeinte mit einer Vision: „Vom lichtbeglänzten Gipfel eines Berges“ geht ein trostloser Zug von Gestalten, denen ihre „Laster und Entartung“ anzusehen sind (gemeint sind Kriminelle, durch ihr Verschulden aber auch durch Elend Verkommene, ebenfalls ,, hartherzige Unternehmer"). In derselben Zeit steigt eine „Kavalkade lichtumflossener Gestalten“ den Berg hinauf, die irgendeine „Größe“ kennzeichnet, sei es im Leid, sei es in der Liebe. „Sie werden sterben, bevor sie ihn [den Gipfel] erreichen, aber sie werden hingelangen: durch Tod zum Licht.“ (NOSSIG 1905a:26f.) Das ,erneuerte Drama "wird eben solche zum Licht strebenden Gestalten zeigen, während der Naturalismus den anderen Menschenzug porträtiert. Durch Kontraste zu anderen Kunstströmungen erklärt Nossig seine Ästhetik der ,Aszension': hier ,Jugend und Gesundheit', da ,greise Morschheit' und ,krankhafte Entartung', hier „Klarheit“, da „,nebelhafte Mystik des Symbolismus“ (NossIG 1905a:39), aber sollte man denken, er betreibe einen Exklusivismus und halte einen Teil der Wirklichkeit für nicht darstellungswürdig, so erläutert Nossig weiter: „Der Naturalist zeigt uns die Bestie im Menschen; der Aszensionist den Menschen in der Bestie.“ (NOSSIG 1905a:29) Diese in seinen Augen nicht deformierende Sicht des Menschen, die das Wahre mit dem Schönen vereinigt, bezeichnet er noch anders als „Ideal-Realismus“ (NossIG 1905a:38) und bemüht sich noch einmal zu zeigen, dass er die ganze Wirklichkeit erfasst und dass diese Wirklichkeitserfassung kein ästhetischer Sozialdarwinismus ist:

Es naht die Epoche der Sozialisierung, welche den Individuen und den Völkern freieste Entwicklung sichern, Eisen und Blut durch Recht vertreten, die Klassen und Nationen trennenden Schranken niederreißen und auf dem Boden wahrer 
Menschenliebe einen bisher unerreichten, idealen Aufschwung der Weltkultur ermöglichen will. Das charakteristische Kennzeichen dieses Idealismus aber [...] ist es, daß er nicht mehr, wie das Christentum der Evangelien, eine weltfremde Heillehre ist, sondern seine hohen Ziele mit praktischen Mitteln anstrebt, also ein Real-Idealismus ist. (Nossig 1905a:41f.)

Es ist eine Vision, die sich nicht wesentlich von der aus dem Monolog Giordano Brunos in Nossigs polnischem dramaturgischem Debüt unterscheidet und deren antipartikularistischen Grundton wir hier auch in den Empfehlungen zum Nationalen in der Kunst wiederfinden: die nationale Kunst dürfe nicht ,ins Lokal-Partikularistische ausarten“ und sollte die „Allgemeinverständlichkeit und Allgemeingültigkeit“ bewahren. (NossIG 1905a:35, 33)

\section{Moderne jüdische Dichtung}

Zwei Jahre nach der Erneuerung des Dramas gab Nossig eine Broschüre über moderne jüdische Literatur heraus, aber auch ihre Lektüre zeigt sich wenig ergiebig, wenn man darin programmatische Ideen speziell zur modernen jüdischen Literatur sucht. In dieser Skizze demonstriert Nossig dagegen sein ,integrales Judentum ${ }^{616}$ im literarischen Bereich. Wohlwollend betrachtet er Ghetto-Geschichten, ,jüdische Stoffkreise“, „elementare Kraft“ der national orientierten jungjüdischen Dichtung, aber auch Werke ohne direkten nationalen Bezug, schließlich wolle er keinem ,aus einem zelotischen Nationalismus" Vorwürfe machen, dass er die nationale Flagge nicht heraushänge (NOSSIG 1907:7). Er zeigt sich unparteiisch im Sprachenstreit und würdigt jüdische Schriftsteller, die Hebräisch, Jiddisch und in den Sprachen der umgebenden Völker schreiben. Solange die Juden im Exil lebten, sollten sie „,in brüderlicher Gemeinschaft mit den [sie] [...] umgebenden Völkern“ wirken (Nossig 1907:7). Doch eine längere Passage widmet Nossig der Polemik mit denjenigen, die ,das Jüdische verächtlich Jargon nennen und als verdorbenes Deutsch, als Korrelat von Schmachtlocken und halbasiatischer Unreinlichkeit, [...] als eine Schande der Judenheit betrachten“ (NossIG 1907:3). Linguistische Argumente (,Verschmelzung von zwei oder mehreren Idiomen" auch im Falle anderer Sprachen) sowie jiddische Literatur und jiddisches Theater (die Bezeichnung, Yiddisch“ wird zitiert) lassen ihn das Jüdische als „Kultursprache“ bezeichnen. Allerdings unterstreicht Nossig,

16 Er soll verschiedene Richtungen vereinigen: den Kulturzionismus, den praktischen und den politischen Zionismus sowie nichtzionistische Kreise einbeziehen; Nossig (1904) und Nossig (1920:11). 
Iwona Kotelnicka

„eine literarische Blüte“ bereite sich erst vor, und zwar betreffe dies alle Sprachen der Juden, man habe mit einer „Fülle“, einer „Verheißung“ aber noch nicht mit einer „Erfüllung“, mit der „Höhe“ zu tun (NoSSIG 1907:3f.). Aber trotz dieses alle Richtungen integrierenden Grundtons scheint der Verfasser vor allem den Wert der ostjüdischen Kultur und deren menschlichen ,Preis“ hervorheben zu wollen: „Ehret sie [die ostjüdischen Dichter], denn sie sind die Träger und Erhalter des jüdischen Volksgeistes im Exil.“ (NOSSIG 1907:11) Diese recht allgemeine Würdigung der jüdischen Literatur rückt ,Gemeinsamkeiten` der jüdischen Werke bzw. Schriftsteller in den Vordergrund, die Nossig unverhohlen einem ,nationalen Charakter' und letztendlich dem ,Blut“ zuschreibt: „Virtuosentum der Feder“, „thätige Sympathie für Fortschritt und Licht“, ,rege Phantasie“, „scharfer Verstand“, die Fähigkeit, in mehreren Kulturen heimisch zu sein, Eignung für kulturelle Vermittlung, „Agilität“, Vielseitigkeit, Kritizismus und Kreativität, alles in allem seien die Juden „das Salz der Völker und das Ferment der Kulturen“ (Nossig 1907:5f.). Das Autostereotyp des ,nationalen Charakters“ ist eine weitergedachte ,Auserwähltheit", die eine Grundlage auch für künstlerisches Schaffen bildet. Das Jüdische, in den ,natürlichen ' biologischen Grenzen und in der Perspektive der Auserwähltheit, wird weiterhin vor dem universellen Hintergrund betrachtet, mit Ausrichtung auf die Vervollkommnung der Welt „im Einklang mit dem Weltgedanken“, zum Wohl aller, auch wenn das Betätigungsfeld in der gegebenen Situation die Nation ist - der Botschaft des etwa zwanzig Jahre nach dem dramaturgischen Debüt geschriebenen deutschen Dramas Abarbanel zufolge.

\section{Abarbanel}

Abarbanel (1906) ist ein zionistisches Tendenzstück, entstanden nach der Etablierung der Zionistischen Organisation, und - aus der Perspektive der Lebensgeschichte Nossigs - nach seinem Streit mit Herzl auf dem Zionistenkongress 1903, der seinen Ruf in zionistischen Kreisen schädigte und mit dem er sich außerhalb des Main-Stream-Zionismus stellte, und nicht zuletzt nach Herzls Tod. Seit etwa sieben Jahren lebt Nossig schon in Berlin, als Journalist, Bildhauer und eine Art Privatgelehrter. 1902 gründet er den Verein für Statistik der Juden und wirbt in seinen Publikationen für die allmähliche jüdische Kolonisation in den Ländern des Ostens (nicht nur in Palästina). Ferner denkt er in dieser Zeit über die jüdische Literatur und das 
moderne Drama nach, denn seine beiden Publikationen darüber kommen fast zeitgleich heraus.

Abarbanel. Das Drama eines Volkes, ein Versdrama in drei Akten, spielt in Spanien 1492, direkt vor der Vertreibung der Juden durch Isabelle von Kastilien. Der erste Akt, im Palast des königlichen Ministers Lucena, zeigt, wie die antisemitischen Ressentiments in dem scheinbar gut funktionierenden gesellschaftlichen Gefüge durchbrechen und den erfolgreichen Finanzminister und Juden, Don Isaac Abarbanel, als Fremden statuieren, ausstoßen und zum Überdenken der eigenen Haltung zwingen. Das antisemitische Repertoire von Nossigs Spaniern entspricht - wie zu erwarten - den modernen antisemitischen Klischees der Zeit der Dreyfuss-Affäre: Spionage, ,Verjudung ' wichtiger geistiger Berufe (Finanzen, Medizin, Literatur) und Eindringen in die Machtzentren ,durch Fürsten und durch Frauen“ (NossIG 1906:6); die Assimilation sei nach Lucena, dem Hauptideologen des Antisemitismus, keine Lösung, die Taufe verschlimmere noch die ,Verjudung' (,so bringt die Taufe / [d]en Feind von außen uns recht in's Haus“" (NossIG 1906:7). Seine Liste der jüdischen ,Sünden“ beschließt Lucena mit dem ganz modernen ,Blut", das sich mit keinen Anpassungsmaßnahmen übertünchen lasse (NosSIG 1906:7). Auch seine Wortwahl ist modern: „[G]ottverfluchte Rasse“, „Ungeziefer“, „,räud'ge Erben“ der Mauren (NossIG 1906:8). Die von dem attraktiven Abarbanel abgewiesene Donna Violante ergänzt das Bild um jüdische ,Mentalitätsmerkmale“: Ängstlichkeit, Frechheit, „Wüstheit“ (NossIG 1906:15), aufs Geschäft bedachte Verlogenheit.

Abarbanel, ein hoher politischer Beamter, intellektuell, ironisch, witzig elegant, diplomatisch geschickt, und doch unter der glatten Oberfläche ein nachdenklicher, etwas melancholisch anmutender Mann ${ }^{17}$, bemüht sich als Politiker um das allgemeine Wohl. Die Vernunft geht dabei vor dem Imponiergehabe einer unnötigen Kampfes- und Siegeslust im Krieg gegen die Mauren. Mit der Loyalität gegenüber der Krone versucht er auch die Hilfe für seine Glaubensbrüder zu verbinden. Dem jüdischen Aristokraten fehlt die vitale Intensität des Bruno oder des Bar Kochba. Er ist zwar eine herausragende Persönlichkeit mit Ausstrahlung, aber eine, die den vitalen Verlockungen widerstehen kann. Wie der biblische Josef weist er schließlich die einflussreiche Frau eines Ministers am Hofe des spanischen Königs ab, denn er hat ein

17 „Ich kann es nicht. Mir ist es nicht gegeben, / Den Wonnekelch besinnungslos zu leeren. / Erinnerungen gibt's, die es mir wehren. / Ich will der Tugend Krone nicht erstreben, / Doch liegt's ererbt im Blut - ich kann es nicht! / Euch gilt die Liebe als Vergnügen - uns als Pflicht...“(Nossig 1906:13) 


\section{Iwona Kotelnicka}

moralisches Gerüst und Pflichtbewusstsein gegenüber seinem Volk. Er kann das, was die tugendhafte Beruria Bar Kochba wünschte: ,sich selbst bezwingen“ (Nossig 1906:113). Aber dieses ,Sich-Selbst-Bezwingen“ ist im ersten Akt vor allem eine sich selbst auferlegte Kontrolle, die das Leben in zwei Welten erfordert, wie es sich im zweiten Akt zeigen wird. Sucht man nach literarischen Parallelen, so stünde ihm der Held der Juden Lessings mit seiner überlegenen Intelligenz nahe. Doch im kritischen Moment des ersten Akts, als Abarbanel das Vertrauen wegen seiner „Fremdheit“ aufgekündigt wird, hält er „mit Leidenschaft“ einen Monolog, der auf den berühmten Monolog Shylocks aus dem Kaufmann von Venedig anspielt:

Wir - fremd? Mit welchem Rechte sagt man das?

Sind wir gleich euch nicht Söhne dieser Erde?

Geht auf die Friedhöfe! Stumm zeugen sie,

Daß wir seit fünfzehnhundert Jahren

Gleich euch dies Land bewohnen! Sprache, Sitten,

Was Menschen eint, was sie zu Brüdern macht,

Das alles haben wir mit euch gemein;

Jerusalem ist uns ein Heiligtum

Wie Rom der Christenheit, dem Islam Mekka!

Fest wurzeln wir im Boden, der uns zeugte:

Ich kenne keinen unter uns, der nicht

Sein Letztes gäbe, wenn es Fürst und Land

Verlangt! Und wir sind fremd? Uns traut man nicht? (Nossig 1906:27) ${ }^{18}$

Nach dem Spionagevorwurf wendet sich also Abarbanel von der spanischen Welt ab, weil diese seine doppelte Identität nicht akzeptiert. Doch der zweite Akt stellt seinen Monolog gegen den Vorwurf der Fremdheit in Frage. In der Studierstube des Weisen Aboab findet Abarbanel zu sich selbst, indem er auf seinen Versuch, in zwei Welten zu leben, kritisch schaut und darin den Grund seines seelischen Leids erblickt: „Es ging ein tiefer Riß durch meine Seele: Den Juden fremd, den Fremden Jude, fühlt' ich [d]ie Judenlüge und das Judenweh..." und schließlich ,Sie haben recht! Wir sind ein fremdes Volk [...].“ (Nossig 1906:30) Er entdeckt sein bisher verschleiertes ,Stammge-

18 Hier die gemeinten Zeilen von SHAKESPEARE (1979), dritter Aufzug, erste Szene: „Hat nicht ein Jude Augen? Hat nicht ein Jude Hände, Gliedmaßen, / Werkzeuge, Sinne, Neigungen, Leidenschaften? Mit derselben Speise genährt, mit denselben Waffen verletzt, denselben Mitteln geheilt, gewärmt und gekältet / von eben dem Winter und Sommer als ein Christ? Wenn ihr uns stecht, bluten wir nicht? Wenn ihr / uns kitzelt, lachen wir nicht? / Wenn ihr uns vergiftet, sterben wir nicht?" (Übersetzt von August W. Schlegel) 
fühl“ (Nossig 1906:31) und durch Sulamit, die weise Tochter des Aboab noch bestärkt (oder ,ergänzt'), wird er zum Zionistenführer.

Die Nachricht über die beschlossene Verbannung aller Juden aus Spanien trifft ein, als der zionistische Durchbruch in emotionaler Aufwühlung des Zwiegesprächs zwischen Sulamit und Abarbanel bereits vollzogen war. Als die beiden die Nachricht vernehmen, sieht man ihnen eher ,freudige Verklärung“ als Verzweiflung an. „Das ist ein Hieb, wie jener Alexanders - Der löst den Knoten! Heil dir!“ sagt Abarbanel, und Sulamit ruft „Hosiannah!“ (Nossig 1906:38) Die Verbannung soll den Impuls zur ,Tat' geben, und dieser im Drama nur angekündigten Tat geht eine Auseinandersetzung um die jüdische Politik voraus, die den gesamten dritten Akt füllt.

Im Gebetraum wird beraten, wie man auf das Edikt über die Verbannung reagieren sollte, und wartet auf Don Senior, der beim König die Zurücknahme der Entscheidung erwirken will. Die Debatte kristallisiert sich um zwei Persönlichkeiten mit Führungsanspruch: Montalto und Abarbanel. Während Abarbanels Stellungnahme als ,Heimkehr' nach Zion von vornherein klar ist, steht das Haupt der Gemeinde, Montalto, vor der neuen Situation eigentlich ratlos da und denkt laut nach, staunt und empört sich. Montalto ist konzipiert als eine Gestalt des Galuth-Juden, der sich an die Bedingungen des Exils materiell und mental angepasst hatte. Er beherrscht Verhaltensstrategien (Bestechung und Bitten), die den Juden zur Verfügung stehen, und akzeptiert diese Situation als normal. Das Leben in Spanien hat er - trotz allerlei Einschränkungen - zu schätzen gelernt, fühlt sich selbst als Spanier und Jude und kann es nicht begreifen, wie ein Land mit „Ordnung“ und „Bildung" die Juden verbannen kann. Er, der Vernünftige, kann die Illusion nicht fallen lassen, dass der König an seinen Juden hängt und sie doch nicht gehen lässt. Sollte es schon zur Verbannung kommen, so erscheint es ihm ratsam, in reiche Länder der spanischen Kultur zu emigrieren, wo das Militär die Ordnung sichert, und dort die alte Gesellschaftsstruktur der Gemeinde zu rekonstruieren (mit dem alten materiellen Status, beruflichen Profil und der Wohltätigkeit gegenüber den Mittellosen). Dem Zionismus Abarbanels hält er als unüberwindbares Hindernis die einseitige Berufsstruktur der Juden entgegen, die in einer nur jüdischen Gesellschaft nicht funktionieren könnte: „,Der Jude kann vom Juden bloß nicht leben“, ,„e]r [der Jude] wirkt mit dem Gehirn, nicht mit der Hand“, ,zum Pflügen, Bauen, Morden [s]ind andere da“ (Nossig 1906:51f.). Darauf entgegnet Abarbanel mit der rhetorischen Frage: „Der Knechtschaft Folgen nehmt Ihr für Natur?“ und bekommt gleich eine Unterstützung vom Steinmetz Cendor, der selbstbewusst auf die von ihm 
Iwona Kotelnicka

praktizierte, glückliche Verbindung von körperlicher Arbeit und geistiger Betätigung hinweist (NossIG 1906:52). ${ }^{19}$

In dem Kampf um die Seelen der versammelten Juden stehen sich in Abarbanel diplomatische Taktik und ehrlicher Stolz, Petrifizieren und Umgestalten der alten Lebensformen, ein passives ,Sich-Treiben-Lassen' und eine entschlossene ,Tat' gegenüber. Montalto stellt sich mit seinen Erwartungen an Sicherheit und Ordnung unwillkürlich auf die Seite der Machthaber, als der Schwache, der Schutz vom Stärkeren braucht, Abarbanel predigt die eigene selbstbestimmte Stärke. Das reformatorische Potential des Zionismus ist hier offensichtlich, aber unterschwellig auch das subversive, denn sobald sich die Juden Zion zuwenden, hören sie auf, die Gewaltstrukturen zu stützen. War die Stärke in Bar Kochba, wenn nicht ein Freibrief zum Immoralismus, dann eine partielle Rechtfertigung des Unmoralischen, so ist sie hier der beste Garant fürs Ethos: Arbeitsethos, soziales Engagement, Mut und Widerstand gegen Ungerechtigkeit. Eine Konfrontation mit messianischen Erwartungen erleben wir auch in diesem Drama, allerdings weniger theatralisch als in den zwei ersten: Sie sind ein argumentatives Problem bei der Entscheidung für oder gegen den Zionismus. Die Rückkehr nach Zion, für die messianische Zeit prophezeit, wird von dem orthodoxen Rabbiner Bar-Elisa (eine Parallelfigur zu Meir in Bar Kochba) abgelehnt, denn es fehlen die Zeichen der Ankunft des Messias. Der weise Aboab, ebenfalls Rabbiner (wie Akiba in Bar Kochba), hält sich nicht an den Buchstaben der Schrift und sieht im Menschen das Subjekt der Geschichte: „,Vollenden ist nicht unsre Pflicht, jedoch Beginnen!““ Die messianische Botschaft lässt Nossig seinen Abarbanel als menschliches, evolutives Handeln in einem gereimten Spruch formulieren: „So wird uns das Exil zum Freiheitsstreben, [s]o machen wir Messias Wege eben!“ (Nossig 1906:49)

19 Bei der durch den Zionismus propagierten Aufwertung körperlicher Arbeit und des ,Muskeljudentums“ MAX Nordaus (1900) konnte Nossig auf sein altes Konzept des Renaissance-Menschen verweisen und es hier auf die nationaljüdische Renaissance übertragen. In seinem Fall scheint ein starker lebensreformerischer Impuls von John Ruskin ausgegangen zu sein, der die künstlerisch-schöpferische und gesundheitlich-ästhetische Komponente des ,integralen Menschen “ in seiner Ganzheitsphilosophie unterstrich und dessen Schriften lange schon im kulturellen Umlauf waren. Als die deutsche Übersetzung um 1900 erschien, widmete ihr Nossig auch recht viel Platz in seinen Feuilletons in der Norddeutschen Allgemeinen Zeitung. Vgl. Nossig (1900a, 1900b) und RUSKIN (1977:LVII). 
Alfred Nossigs Dramen. Identitätsprojektionen und biographische Bezüge

\section{Biographische Bezüge}

Nossigs auf Deutsch erschienenes Drama wurde in Polen bemerkt, und ein junger, nicht ganz unvoreingenommener Rezensent der Warschauer Zeitschrift Izraelita (Freidenker und Antizionist), erlaubte sich nach der Würdigung vor allem des „Verses“ und „einiger dekorativ-szenischer Ideen“ eine boshafte Subsumierung: „Ein Riesenberg von Inspiration kreißte und gebar eine... mickrige zionistische Maus!“ (B[ELMONT] 1906:431) Doch trotz der offensichtlichen Tendenz, die von dem Warschauer Rezensenten als „naivzionistisch“ bezeichnet wurde, gibt es im Drama zwei Spuren, die ein gewisses biographisches Gewicht haben und nicht ganz auf der Hand liegen. Die erste betrifft die Auseinandersetzung mit dem politischen Zionismus, deren Höhepunkt Nossigs einsamer Kampf gegen Herzl auf dem zionistischen Kongress (1903) war. Nossig hielt dessen diplomatischen Bemühungen um die politische Anerkennung der jüdischen Ansprüche in Palästina eine organische ,Gegenwartsarbeit‘, allmähliche Ansiedlung im ganzen Nahen Osten entgegen und kritisierte die Mittelverschwendung für die bisherigen politischen Aktivitäten. Über den Zusammenstoß mit dem charismatischen Führer Herzl berichtete die Presse, so dass man in Warschau selbst nach einigen Jahren von dem Anathema lesen konnte, mit dem Nossig nach diesem Vorfall in zionistischen Kreisen belegt worden war. (JUG. 1907:17) Abarbanels Vision enthält polemische Akzente gerade gegen den politischen Zionismus: „nicht mit einem Schlag kommt man an's Ziel“", zuerst könne man den Tempel aufbauen, und er würde wie ein Magnet auf die zerstreuten Juden wirken. „Stets war der Islam uns ein bessrer Freund“, und mit Ägypten und der Türkei hätte man sich schon lange absprechen können; „,das große Werk“ müsse „Schritt für Schritt“ verwirklicht werden. Anfangen sollte man jetzt, denn ,[l]ocker hängt [d]as Land heut an dem Reich der Mameluken, wie eine Frucht, die fallen will“ (Nossig 1906:46, 49, 50). Die zweite Spur, eine weniger deutliche, führt zu Alfaro, einer intriganten Gestalt, die in der Beratung an Stelle von Argumenten eine Verunglimpfungstaktik gegenüber Abarbanel einsetzt. Wie die spanischen Antisemiten im ersten Akt, wirft er ihm Geltungsdrang und Spionage vor. Ob diese Anfeindungen gegen Abarbanel einen aktuellen Bezug zu Nossig persönlich haben und als verschlüsselte Verteidigung vor solchen Einwänden eingebaut wurden, ist nicht auszuschließen, denn solche Einwände wird Nossig gekannt haben. ${ }^{20}$

20 Angefangen mit den Vorwürfen wegen seiner Broschüre, in der Kaiser Wilhelm positiv dargestellt wurde (Nossig 1900) und der er seine Arbeit bei der Nord- 


\section{Iwona Kotelnicka}

Nach dem Zweiten Weltkrieg greift der polnisch-jüdische Schriftsteller Roman Brandstaetter das Drama Abarbanel im biographischen Kontext auf, als er seine Begegnung mit Nossig auf das im Ghetto vollstreckte Urteil indirekt extrapoliert. Die beiden trafen sich in den 1930er Jahren in Warschau, und Nossig zeigte ihm die Abbildungen seiner Skulpturen. Brandstetter notiert Details, die aus der Perspektive des Urteils die dunklen Kammern der Seele des - wie er annimmt - künftigen Verräters wenigstens etwas ausleuchten könnten (die Skizze heißt: Judas oder das Herz der Finsternis). Er konstatiert eine gepflegte, sachliche und doch mit Leidenschaft unterwanderte Kälte, ein [zynisches?] Gelächter, eine gut kaschierte [diabolische?] Gehbehinderung und die Ähnlichkeit Nossigs mit den von ihm porträtierten Propheten. Er versucht auch Nossigs Worte über Nazi-Deutschland zu rekonstruieren. „Vielleicht werde ich hier gebraucht?" (BRANDSTAETTER 1987:19) Irgendwann erreiche Hitler seine Ziele, und dann werde man sich mit ihm absprechen müssen, um das zu retten, was noch zu retten sein werde. Zum Schluss des Treffens holte Nossig das Drama Abarbanel aus der Mappe und machte Brandstaetter den Vorschlag, das Stück ins Polnische zu übersetzen. Auf die Frage, wozu eine polnische Übersetzung nötig sei, antwortete Nossig nach den Worten Brandstaetters, er wolle dem Regisseur Arnold Szyfmann eine Aufführung vorschlagen, um sich nach so vielen Jahren in der polnischen Gesellschaft in Erinnerung zu bringen. Die gezeigten Bilder der Plastiken und das Drama lassen Brandstaetter keine Ruhe. In den Bildern der Propheten erkennt er Nossigs Gesichtszüge und suggeriert dem Leser, freilich mit Fragezeichen, Abarbanel und die Plastiken wären vielleicht ein Schlüssel zu Nossigs Selbstverständnis: „Kann es sein, dass dieser Mann unter dem Komplex leidet, ein Prophet, der ,Erlöser' seines Volkes [...], ein zeitgenössischer Abarbanel zu sein?“ (BRANDSTAETTER 1987:19) Brandstaetter gibt zwar an, Nossigs Abarbanel nicht gelesen zu haben, aber die historische Gestalt des Isaac Abarbanel war ihm mit Sicherheit hinlänglich bekannt. In der Überleitung zum Todesurteil für den Verrat im Ghetto lässt Brandstaetter die Frage nach dem Warum der Kollaboration (nicht des Urteils) offen. Sein vorsichtiger, mit Fragezeichen versehener Hinweis auf Nossigs Identifikation mit den eigenen künstlerischen und literarischen Projektionen ist zweischneidig, als Verteidigung und Anklage: Wenn man die historische Figur Abarbanels betrachtet - des geistigen Führers der Juden, der durch seine Beziehungen zu

deutschen Allgemeinen Zeitung verdanken sollte, wird er immer wieder unlauterer Intentionen verdächtigt, was ihm sicherlich nicht unbekannt war; s. z.B. LiCHTHEIM (1970:119). 
Alfred Nossigs Dramen. Identitätsprojektionen und biographische Bezüge

den Mächtigen seinen Glaubensbrüdern zu helfen versuchte -, wäre eine solche Identifikation nicht nur Anmaßung und Selbsttäuschung, sondern auch eine Rechtfertigung (Motivation?) der möglichen Kollaboration, hier des ,Teufelspaktes‘. Wenn man jedoch Nossigs Abarbanel liest, sieht man, dass sich diese Figur von der historischen gerade dadurch unterscheidet, dass sie jegliche Kollaboration endgültig aufkündigt. In der literarischen Welt der drei Dramen wird ein Taktieren, dem die Wahrheit zum Opfer fällt, verurteilt: in Tragedia myśli die Taktik des pragmatischen Arztes, der ,vernünftige“ Begründungen für die Selbstverleugnung vorschlägt, in Abarbanel die des edlen Don Senior, der zum König bitten geht und zur Taufe gezwungen wird, und des Alfaro, der den Versammelten eine gemeinsame Taufe als Konzession gegenüber den Spaniern vorschlägt und dafür mit dem Bann belegt wird. In Bar Kochba ist der geschmeidige Ismael ein Spion, der auf den weisen Eleazar den Verdacht des Verrats lenkt, was zu dessen Ermordung führt, und in der letzten Szene lässt der siegreiche Severus den Verräter erhängen: „,Du hast die Deinen verraten, um so eher wirst du uns verraten." (NossiG 1906:174)

Im literarischen Plan finden wir bei Nossig nichts, was an die Tradition des polnischen ,Wallenrodismus ${ }^{21}$, des verdeckten Dienstes bei den Feinden für sein geknechtetes Volk, erinnern könnte. Spione sind in seinen Dramen nur Verräter. Mit einer literarischen Rechtfertigung des politischen Immoralismus haben wir es bei ihm nicht zu tun, der Dramatiker verzeiht nur Sünden aus dem Überschuss an vitaler Energie, nicht aus politischem Kalkül. Das ,doppelte Spiel` als Politik mit anderen Mitteln wird nicht akzeptiert.

\section{Quellen}

AKten Zur DeUtschen Auswärtigen Politik 1918-1945. Serie A. Bd. 4: Gesandtschaftsrat von Dirksen (Warschau) an das Auswärtige Amt. 10.1.1921, 118:236-237.

Simckes, LAZARRE S. (O. J. [2004]): Nossig's Antics. New Haven [unveröffentlicht]. StaAtsbibliothek Zu Berlin. Preussischer Kulturbesitz: Handschriften. Nachla $\beta$ Brümmer.

21 Von ,Konrad Wallenrod` abgeleitet, dem edlen, ein solches doppeltes Leben führenden Titelhelden des berühmten romantischen Poems von Adam Mickiewicz. 


\section{Iwona Kotelnicka}

\section{Literatur}

Almong, Shmuel (1987): Alfred Nossig: A Reappraisal. In: Studies in Zionism 7:1-29.

ANONYM (1888): Teatr literatura i sztuka. [Theater, Literatur und Kunst]. In: Gazeta Narodowa, 28.3.1888:3.

ANONYM (1888a): Teatr literatura i sztuka. [Theater, Literatur und Kunst]. In: Kurier Lwowski, 21.3.88:5f.

B[elmont], L[Eo] (1906): ,Abarbanel‘. Dramat Alfreda Nossiga [,Abarbanel‘. Das Drama Alfred Nossigs]. In: Izraelita 36:431-432.

Bohusz, Maryan (1885): Przeglad literacki. Alfred Nossig: Tragedya myśli. Poemat dramatyczny. [Literarische Umschau. Alfred Nossig. Die Tragödie des Gedankens. Ein Versdrama]. In: Przeglad Tygodniowy Życia Spotecznego, Literatury i Sztuk Pięknych 36:456-458.

BRANDSTAETTER, Roman (1987): Judas czyli jądro ciemności. [Judas oder das Herz der Finsternis]. In: $W$ drodze 4:16-21.

Buber, Martin (1920): Zion und die Jugend. In: Buber, MARTin: Die jüdische Bewegung. Gesammelte Aufsätze und Ansprachen 1916-1920. Berlin, 157-176.

CZERniaKów, ADAM (1983): Adama Czerniakowa dziennik getta warszawskiego 6 IX 1939- 23 VII 1942. [Adam Czerniakóws Tagebuch des Warschauer Ghettos, 6.9.193923.7.1942]. Bearbeitung und Anmerkungen Marian Fuks. Warszawa.

Feldman, Wilhelm (1887): Alfreda Nossiga „Poezje“. Szkic literacki. [Alfred Nossigs „Dichtungen“. Eine literarische Skizze]. In: Izraelita 47:382-383.

Frommelt, Reinhard (1977): Paneuropa oder Mitteleuropa. Stuttgart.

Ge (1885): Z literatury. ,Tragedia myśli‘. Poemat dramatyczny Alfreda Nossiga. Lwów. [Aus der Literatur. „Die Tragödie des Gedankens“. Ein Versdrama Alfred Nossigs. Lemberg]. In: Izraelita 34:273f.

GRAETZ, HEINRICH (1908): Geschichte der Juden von den ältesten Anfängen bis auf die Gegenwart. Bd. 4. Berlin (=Reprint 1998).

IRZYKowski, KAROL (2001): Dziennik. [Tagebuch]. Bd.1: 1891-1897. Kraków.

JUG. (1907): Z prasy rosyjsko-żydowskiej. [Aus russisch-jüdischer Presse]. In: Izraelita $2: 17$.

KACENELSON, ICCHAK ( $\left.{ }^{2} 1986\right):$ Pieśń o zamordowanym żydowskim narodzie. [Das Lied vom ausgemordeten jüdischen Volk]. Aus dem Jiddischen von Jerzy Ficowski. Warszawa.

Kotelnicka, IwONa (2009): Alfred Nossig - ein gescheitertes Leben zwischen Kulturen, Kunst und Politik. In: WeGER, THOMAS (ed.): Grenzüberschreitende Biographien zwischen Ost- und Mitteleuropa. Wirkung - Interaktion - Rezeption. Frankfurt (M.) u. a., 419-444. 
Alfred Nossigs Dramen. Identitätsprojektionen und biographische Bezüge

KuŹNiak, ANgelika / Tuszyńska, Agata (2008): Polacy nie zastuguja na poezje Tuwima. [Die Polen haben Tuwims Poesie nicht verdient]. In: Gazeta Wyborcza. Duży Format: http://wyborcza.p1/1,76842,5849827,Polacy_nie_zasluguja_na_poezje_ Tuwima.html (28.3.2011).

LICHTHEIM, RICHARD (1970): Rückkehr. Lebenserinnerungen aus der Frühzeit des deutschen Zionismus. Stuttgart.

MARESZ, BARbARA / SZydŁowSKA, Mariola (1993): Repertuar Teatru Polskiego we Lwowie 1886-1894. [Das Repertoire der Polnischen Theaters in Lemberg 1886-1894]. Kraków.

MARK, BERNHARD (1959): Walka i zagłada warszawskiego getta. [Kampf und Vernichtung des Warschauer Ghettos]. Warszawa.

Marszatek, AgnieszKa (1992): Repertuar Teatru Polskiego we Lwowie 1875-1881. [Das Repertoire des Polnischen Theaters in Lemberg 1875-1881]. Kraków.

- (1993): Repertuar Teatru Polskiego we Lwowie 1881-1886. [Das Repertoire des Polnischen Theaters in Lemberg1881-1886]. Kraków.

MENDELsohn, EzRA (1971): From Assimilation to Zionism in Lvov: The Case of Alfred Nossig. In: The Slavonic and East European Review XLIX:521-534.

Nordau, Max (1900): Muskeljudenthum. In: Die Welt, 15.6.1900:2f.: http://www. compactmemory.de/index_p.aspx?ID_0=30 (28.3.2011).

Nossig, Alfred: (1885) Tragedia myśli. Poemat dramatyczny. [Die Tragödie des Gedankens. Ein Versdrama]. Lwów.

- (1886): Przyszłość judaizmu. [Die Zukunft des Judaismus]. In: Izraelita 46: 373-374.

- (1887): Próba rozwiąania kwestii żydowskiej. [Ein Versuch zur Lösung der jüdischen Frage]. Lwów.

- (1885 / ${ }^{2}$ 1888): Pamiętnik Daniela. [Daniels Tagebuch]. In: NossIG, ALFRED: Poezje. Lwów, 27-80.

- (1888): Król Syjonu. Tragedja w pięciu aktach. [Der König von Zion. Tragödie in fünf Aufzügen]. In: Nossig, 81-173.

- (1892) Jan Prorok. Opowieść na tle galicyjskim z r. 1880 w dziewięciu księgach. [Jan der Prophet. Eine Erzählung vom Jahre 1880 auf dem galizischen Hintergrund in neun Büchern]. Lwów.

- (1892a) Katalog der Polnischen Abtheilung der Internationalen Musik- und Theater-Ausstellung in Wien. Wien.

- (1894): Die Sozialhygiene der Juden und des altorientalischen Völkerkreises. Stuttgart/Leipzig/Berlin/Wien.

- (1900): Die Politik des Weltfriedens. Die deutsch-französische Annäherung und die Kontinentalunion. Berlin.

- (1900a): Aus der Vogelschau. Plaudereien. In: Norddeutsche Allgemeine Zeitung, 28.1.1900. 


\section{Iwona Kotelnicka}

- (1900b): Das Freskobild der Straße. In: Norddeutsche Allgemeine Zeitung. Beilage, 10.2.1900.

- (1904): Kolonizacya żydowska w Palestynie. [Die jüdische Kolonisation in Palästina]. Lwów.

- (1905): Die Auserwähltheit der Juden im Lichte der Biologie. In: Zeitschrift für Demographie und Statistik der Juden 3:1-5.

- (1905a): Die Erneuerung des Dramas. Berlin.

- (1905b): Jak należy pojmować wybraństwo ludu Izraela? [Wie soll man die Auserwähltheit des jüdischen Volkes verstehen?]. In: Safrus. Ksiązka zbiorowa poświęcona sprawom żydowstwa. Warszawa.

- (1906): Abarbanel. Das Drama eines Volkes. Berlin.

- (1907): Moderne jüdische Dichtung. Berlin.

- (1920): Odbudowa Palestyny. [Der Wiederaufbau Palästinas]. Tel Aviv.

Piber, ANDRZEJ (1978): Nossig, Alfred. In: Rostworowski, EMANUEl et al. (eds.): Polski Stownik Biograficzny. [Polnisches Biographisches Lexikon]. Bd. 23. Wrocław/Warszawa/Kraków/Gdańsk, 236-240.

Prokop-Janiec, Eugenia (1992): Międzywojenna literatura polsko-żydowska. [Die polnisch-jüdische Literatur der Zwischenkriegszeit]. Kraków.

ReHM, Walter (1924): Das Werden des Renaissancebildes in der deutschen Dichtung vom Rationalismus bis zum Realismus. München.

RingelBlum, EMANUEL (1988): Kronika getta warszawskiego wrzesień 1939-styczeń 1943. [Chronik des Warschauer Ghettos September 1939-Januar 1943]. Einführung und Redaktion Artur Eisenbach. Warszawa.

RUSKIN, JoHN (1977): Sztuka społeczeństwo wychowanie. [Kunst Gesellschaft Erziehung]. Wrocław u. a.

SADKOwska, KataRzYna (2007): Irzykowski i inni. Twórczość Fryderyka Hebbla w Polsce 1890-1939. [Irzykowski und andere. Das Schaffen Friedrich Hebbels in Polen 1890-1939]. Kraków.

ShaKesPeare, William (1979): Der Kaufmann von Venedig. Zürich: http://gutenberg. piegel.de/buch/2194/14 (28.3.2011).

TZUr, Eli (2001): Collaboration. In: LAQUeR, WALTER (ed.): The Holocaust Encyclopedia. New Haven/London, 127-133.

Z. (1885): Alfred Nossig: Tragedya Myśli. In: Prawda 17:200. 